\title{
Maspin enhances cisplatin chemosensitivity in bladder cancer T24 and 5637 cells and correlates with prognosis of muscle- invasive bladder cancer patients receiving cisplatin based neoadjuvant chemotherapy
}

Jinbo Chen ${ }^{1}$, Long Wang ${ }^{1}$, Yunhua Tang ${ }^{1}$, Guanghui Gong², Longfei Liu', Minfeng Chen ${ }^{1}$, Zhi Chen ${ }^{1}$, Yu Cui ${ }^{1}$, Chao Li $i^{1}, \mathrm{Xu}$ Cheng ${ }^{1}$, Lin $\mathrm{Qi}^{1}$ and Xiongbing $\mathrm{Zu}^{1^{*}}$

\begin{abstract}
Background: Maspin, a non-inhibitory member of the serine protease inhibitor superfamily, has been characterized as a tumor suppressor gene in multiple cancer types. Chemotherapeutic insensitivity is one of major obstacles to effectively treating muscle invasive bladder cancer (MIBC). This study was conducted to investigate the role and probable mechanism of Maspin enhancing cisplatin chemosensitivity of bladder cancer in vitro and MIBC patients.

Methods: Maspin expression was quantified by qRT-PCR in two MIBC cell lines (T24 and 5637). After successful established Maspin overexpression model by lipidosome transfection, MTT and cell apoptosis assay were used to assess the MIBC's cisplatin sensitivity. Western blot method was used to test PI3K AKT/mTOR signal passway and apoptosis related molecules Caspase 3 and Bcl-2. Additionally, we evaluated Maspin expression and prognosis in 62 MIBC cases who underwent cisplatin based neoadjuvant chemotherapy (NACT) using immunohistochemistry.

Result: Upregulate Maspin expression could enhance the chemosensitivity induced by cisplatin in T24 and 5637 cell lines. The cell viability, cloning ability and IC50 were reduced while apoptosis rate was upregulated when cells were transfected Maspin. Phospho(p)-AKT, PI3K, mTOR, and Bcl-2 expression were significantly decreased, whereas Caspase 3 was greatly increased in the Maspin group. In the clinic study, there was significant correlation between Maspin expression and overall survival (OS) and progression-free survival (PFS) rate in MIBC patients who received cisplatin based NACT.
\end{abstract}

Conclusion: Maspin could enhance cisplatin chemosensitivity in T24 and 5637 cell lines. Its expression correlated with prognosis of MIBC patients who received cisplatin based neoadjuvant chemotherapy.

Keywords: Maspin, Muscle invasive bladder cancer, Cisplatin, Chemosensitivity

\footnotetext{
* Correspondence: whzuxb@163.com

Jinbo Chen and Long Wang worked as co-first authors for this manuscript.

${ }^{1}$ Department of Urology, Xiangya Hospital, Central South University,

Changsha, Hunan 410008, China

Full list of author information is available at the end of the article
} 


\section{Background}

Bladder cancer is one of the most common types of urinary tract malignancy, with an estimated 429,800 new cases of bladder cancer and 165,100 deaths occurred in 2012 worldwide. Incidence rates are highest in Europe, Northern America, Western Asia, and Northern Africa [1]. It is clinically characterized by its progression, recurrence, metastasis, and drug resistance [2]. At initial diagnosis, approximately $70 \%$ of cases are diagnosed as non-muscle invasive bladder cancer (NMIBC) and approximately $30 \%$ as muscle-invasive bladder cancer (MIBC) [3]. Although the majority of patients presenting with superficial disease have a favorable prognosis, approximately $70 \%$ of these develop disease recurrence and 10 to $20 \%$ of these patients progress to MIBC $[4,5]$. The standard treatment for MIBC is radical cystectomy, which only provides a mere five-year survival rate of $50 \%$ [6]. In order to improve the effects of treatment, perioperative chemotherapy has been explored since the 1980s. Although cisplatin is the first-line chemotherapy for advanced bladder cancer, the cisplatin/gemcitabine (GC) regimen has a median time-to-progression of only six months and has no effect on overall survival after radical cystectomy in high-risk patients [7]. Cancer cell resistance to cisplatin is a major obstacle to the effective treatment of bladder cancer, and the underlying mechanisms of the resistance are unclear till now.

Maspin (mammary serine protease inhibitor), is a member of the serine protease inhibitor/non-inhibitor superfamily. Recent studies showed it was a tumor suppressor gene in multiple cancers. Its effects included inhibition of cancer cell invasion, attachment to extracellular matrices, increased sensitivity to apoptosis, and inhibition of angiogenesis $[8,9]$. Maspin expression was found in high quantities in normal urothelium. It was preserved in superficial bladder cancer but significantly diminished in invasive carcinoma. And within the group of invasive cancers, it was found that maspin expression was associated with good prognosis [10]. There were some reports of Maspin enhancing chemosensitivity in ovarian and breast carcinoma cells $[11,12]$. Also, clinic relevance of Maspin expression and adjuvant chemotherapy prognosis in advanced gastric cancer was confirmed [13]. But its role and mechanism in chemosensitivity of bladder cancer remain unclear. So, in the current study, we investigated the role and probable mechanism of Maspin enhancing the cisplatin chemosensitivity of bladder cancer in vitro and MIBC patients.

\section{Methods}

\section{Cell culture}

The MIBC cell lines T24, 5637 and human bladder epithelial cell line SV-HUC-1 were obtained from American Type Culture Collection (ATCC). Cells were cultured in
1640 medium (Invitrogen, Carlsbad, CA) with $10 \%$ FBS (Invitrogen) and $1 \%$ penicillin/streptomycin (Invitrogen). All cells were cultured in a sterile incubator maintained with $5 \% \mathrm{CO} 2$ at $37^{\circ} \mathrm{C}$.

\section{Real-time RT-PCR}

Total RNA was extracted from cells with Trizol reagent (Invitrogen) according to the manufacturer's instructions. The relative expression level of Maspin was determined by quantitative real-time RT-PCR using standard SYBR Green RT-PCR Kit (Takara, Otsu, Japan). The specific primer pairs are as follows: Maspin sense, $5^{\prime}-\mathrm{CT}$ GACAACAGTGTGAACGAC-3', antisense, 5' -CAAGC CTTGGGATCAATC ATCT-3'; $\beta$-actin as an internal control, sense, 5' -AGGGGCCGGACTCGTCATAC T-3' and antisense, 5'-GGCGGCACCAC CATGTACCCT-3' . The relative expression of Maspin mRNA was quantified using the GraphPad Prism 4.0 software (GraphPad Software, San Diego, CA, USA) and $2^{-\Delta \Delta C t}$ method.

\section{Western blot analysis}

Protein levels were quantified by Bradford assay. The protein sample was diluted, heated for denaturation, and then subjected to dodecyl sulfate polyacrylamide gel electrophoresis (SDS-PAGE) and transferred onto polyvinylidene fluoride membranes (PVDF, Millipore). The membrane was blocked in $0.1 \%$ Triton X-100 and $5 \%$ non-fat milk powder in phosphate-buffered saline for $1 \mathrm{~h}$ at $4{ }^{\circ} \mathrm{C}$ and then probed with $\beta$-actin (1:2000, Santa Cruz Biotechnology, Santa Cruz, CA) rabbit polyclonal primary antibody. After washing 3 times with Trisbuffered saline Tween (TBST), the membrane was incubated in peroxidase-conjugated goat anti-rabbit IgG antibody (1:4000, Immunoway, USA). Bands were visualized by an enhanced chemiluminescence detection system using medical X-ray films and quantified by IPP6.0 analysis software. The intensities of band of interest were expressed relative to the $\beta$-actin intensities from the same sample.

\section{Transfection}

Cells were trypsin-digested and seeded onto six-well plates the day prior to the transfection to ensure $60-70 \%$ cell confluence on the day of transfection. pcDNA3.1-Maspin recombinant plasmids were constructed (Data not shown) and transfected into T24 and 5637 cell lines using Lipofectamine 2000 (Invitrogen) according to the manufacturer's recommendations. pcDNA3.1 without Maspin plasmids were also transfected into these two cell lines as negtive control (NC) groups.

\section{Cell proliferation assay}

Cells in exponential growth were plated at a concentration of $3 \times 10^{3}$ cells/well in 96-well plates for $24 \mathrm{~h}$ before use. 
The culture medium was replaced with fresh medium containing cisplatin with different concentrations for $72 \mathrm{~h}$. Next, MTT (20 $\mu \mathrm{l} /$ well) was added to each well. After $2 \mathrm{~h}$ further incubation, the optical density at $570 \mathrm{~nm}$ (OD570) of each well was measured with an ELISA reader (ELX800, Bio-Tek). The inhibition rate for every concentration and the IC50 (the concentration of drug that results in $50 \%$ of the control value) were calculated using Graphpad5 software.

\section{Cell apoptosis assay}

Forty-eight hours after transfection, all group cells were seeded at a density of $5 \times 10^{5}$ cells per $10-\mathrm{mm}$ dish, and treated with cisplatin at proper concentration for $24 \mathrm{~h}$, respectively. Then the cells were collected by brief trypsinization and washed twice in PBS. After incubation with $5 \mu \mathrm{l}$ of Annexin V-FITC and $10 \mu \mathrm{l}$ of propidium iodide (PI) at room temperature for 15 min in dark, cells were analyzed by flow cytometry (BD, NJ, USA). Apoptosis cells were recognized as high Annexin V fluorescence signal with low PI signal. The percentages of apoptotic cells were calculated by data from FACS analysis.

\section{Colony-formation assay}

For all groups, $3 \mathrm{ml}$ complete medium containing 150 cells were added to each well of a six-well plate. Plates were incubated at $37{ }^{\circ} \mathrm{C}, 5 \% \mathrm{CO}_{2}$ for 14 days. After that, cells were gently washed and stained with Giemsa. Colonies containing at least 50 cells were counted.

\section{Patients and tumor samples}

From January 2010 to January 2014, 62 MIBC patients who received cisplatin based neoadjuvant chemotherapy (NACT) and laparoscopic radical cystectomy and pelvic lymph node dissection (RC-PLND) in our center were included in this study. We obtained ethics approval from the ethics committee at Xiangya Hospital, Central South University. Written informed consent was obtained from all participants in our study. Table 1 showed details of patients and tumor characteristics. Follow-up information was available for all 62 patients with a follow-up time of 36.1 (range from 16 to 64) months. Tumor staging was determined by 2009 UICC-TNM staging system and tumor grading was according to 1973 WHO grading system. The chemotherapy of GC regimen were as follows: gemcitabine $1000 \mathrm{mg} / \mathrm{m}^{2}, 1 \mathrm{~d}-1,8 \mathrm{~d}-1$; cisplatin $70 \mathrm{mg} / \mathrm{m}^{2}, 2 \mathrm{~d}-1$. a 21-day cycle for 3-4 cycles. NACT was administered GC regimen within 16 weeks before surgery.

\section{Tissue immunohistochemistry}

Immunohistochemical (IHC) staining for Mapsin protein was carried out using an SP ready-to-use kit (Zhongshan Jinqiao Biotechnology, Zhongshan, China) according to the
Table 1 Patient Characteristics

\begin{tabular}{ll}
\hline Total patients (n) & 62 \\
\hline Age (year) & $60.5(39-78)$ \\
Gender (n, \%) & \\
$\quad$ Male & $43(69.4 \%)$ \\
Female & $19(30.6 \%)$ \\
Grade $(n, \%)$ & \\
Grade 1 & $4(6.5 \%)$ \\
Grade 2 & $30(48.4 \%)$ \\
Grade 3 & $28(45.1 \%)$ \\
TNM stage (n, \%) & \\
pT2N0 & $14(22.6 \%)$ \\
pT2N+ & $5(8.1 \%)$ \\
pT3N0 & $11(17.7 \%)$ \\
pT3N+ & $16(25.8 \%)$ \\
pT4aN0 & $3(4.8 \%)$ \\
pT4aN+ & $13(21.0 \%)$ \\
Follow-up time (months) & $36.1(16-64)$ \\
\hline
\end{tabular}

manufacturer's recommendation. Briefly, deparaffinization and rehydration were done before paraffin-embedded sections $(4 \mu \mathrm{m}$ thick) were immersed in 0.01 Mcitric buffer ( $\mathrm{pH}$ 6.0). The slides were then incubated with $3 \%$ hydrogen peroxide for $10 \mathrm{~min}$, followed by incubation in normal goat serum for $10 \mathrm{~min}$ at room temperature. Maspin antibody (monoclonal mouse antibody; NCL-Maspin, Novocastra Laboratories Ltd.) was used at a dilution of 1: 200 as the first antibody according to the manufacturer's instructions. Sections were then incubated with goat anti-polyvalent antibody for $10 \mathrm{~min}$ and subsequently with streptavidin peroxidase for $10 \mathrm{~min}$. The slides were visualized using diaminobenzidine and counterstained with hematoxylin before microscopy.

The IHC score was assessed independently by two surgical pathologists. The number of immunoreactive cells was quantified as 'proportion score', including 0; no immunoreactive cells, 1 ; the numbers of immunoreactive cells were less than $1 \%, 2$; less than $10 \%$, 3; less than one-thirds, 4; less than two-thirds, 5; more than twothirds. The highest number of immunoreactive tumor cells was graded as 'intensity score', including 0; no immunoreactivity, 1 ; weak staining intensity, 2 ; intermediate, 3; strong. The IHC results were grouped based on the IHC score (proportion score plus intensity score): $0-2$, negative $(-) ; 3-8$, positive $(+)$. In case of disagreement, the score was reevaluated and consensus was reached [14].

\section{Statistical analysis}

Results were expressed as the means \pm standard deviation (SD) from at least three separate experiments. Statistical 
analysis was carried out using SPSS 16.0 software. Student's $\mathrm{t}$-test was used to compare the relative amounts of mRNAs and proteins. Survival curves were plotted by the KaplanMeier method, and differences were examined by the logrank test. A value of $P<0.05$ was considered to indicate statistical significance.

\section{Results}

\section{Different expression of Maspin in bladder cancer and} normal bladder epithelial cell lines

To delineate the potential role of Maspin in bladder cancer, we compared the protein level in bladder normal and cancer cells. The protein levels of Maspin in MIBC cell lines were determined using western blot. Downregulation of Maspin was observed in bladder cancer cell lines. The densitometry evaluation of the western blots showed that Maspin expression was significantly decreased in bladder cancer T24 and 5637 cell lines as compared the control group SV-HUC-1, respectively. $(P<0.05)$ (Fig. 1a, b). These results suggest that Maspin may play an important role in malignant progression of bladder cancer.

\section{Expression levels of Maspin post-transfection in bladder cancer T24 and 5637 cells}

To clarify the functions of Maspin in bladder cancer T24 and 5637 cells, gain-of-function cell models were constructed by transfecting with pcDNA3.1-Maspin. Compared with blank control group (Con) and negative control group (NC), Maspin mRNA (Fig. 2a, b) and protein (Fig. 2c, d) level was significantly up-regulated when transfected with pcDNA3.1-Maspin in T24 and 5637 cells $(P<0.05)$.

\section{Maspin inhibits proliferation and enhancing the sensitivity to cisplatin of bladder cancer T24 and 5637 cells}

To investigate the effects of Maspin on proliferation and sensitivity to cisplatin of bladder cancer T24 and 5637 cells, we used MTT and colony formation assay. The results showed both cells viability were reduced with the increasing of cisplatin concentrations. Overexpression of Maspin dramatically decreased the survival rate (Fig. 3a) of both T24 and 5637 cells as compared with that of Con and NC group $(P<0.05)$. The IC50 results showed that Maspin overexpression increased the sensitivity of both T24 and 5637 cells to cisplatin, with the IC50 value decreasing from $23.32 \pm 4.30 \mathrm{mg} / \mathrm{l}$ to $15.30 \pm 2.10 \mathrm{mg} / \mathrm{l}$ and from $4.91 \pm 0.42 \mathrm{mg} / \mathrm{l}$ to $2.14 \pm 0.21 \mathrm{mg} / \mathrm{l}$, respectively (Fig. 3b). Also, clone-formation assay showed the cells proliferation were inhibited in Maspin group of T24 and $5637(P<0.05)$ (Fig. 3c, d). It suggested that Maspin could inhibit the proliferation and enhance sensitivity to cisplatin of T24 and 5637 cells.

\section{Maspin increase cell apoptosis induced by cisplatin in T24 and 5637 cells}

To determine whether the Maspin-induced growth inhibition was mediated by apoptosis, we further used the flow cytometry to identify the cell apoptosis rate. We evaluate the influence of Maspin on T24 and 5637 cells apoptosis induced by $25 \mathrm{mg} / \mathrm{L}$ and $6 \mathrm{mg} / \mathrm{L}$ cisplatin. As showed in Fig. 4, the apoptosis rates were elevated in all group (Con, NC and Maspin) when adding the cisplatin. Overexpression of Maspin increase T24 and 5637 cells apoptosis at about 12.48 and $12.53 \%$ (from 15.60-28.08\% and from $19.70-32.23 \%)$, respectively. $(P<0.05)$. This was consistent with the change of drug sensitivity and demonstrated that Maspin induced chemosensitivity alteration was probably mediated by the cell apoptosis pathway.

\section{The probable mechanism of upregulation of Maspin enhances cisplatin-induced chemosensitivity in T24 and 5637 cells}

To further elucidate the probable mechanism of Maspin enhancing cisplatin-induced chemosensitivity in T24 and 5637 cells, western blotting analysis was used to examine the effects on AKT, phospho(p)-AKT, PI3K, mTOR, Caspase 3 and $\mathrm{Bcl}-2$ protein expressions. All groups were conducted after cells culture in IC50 cisplatin

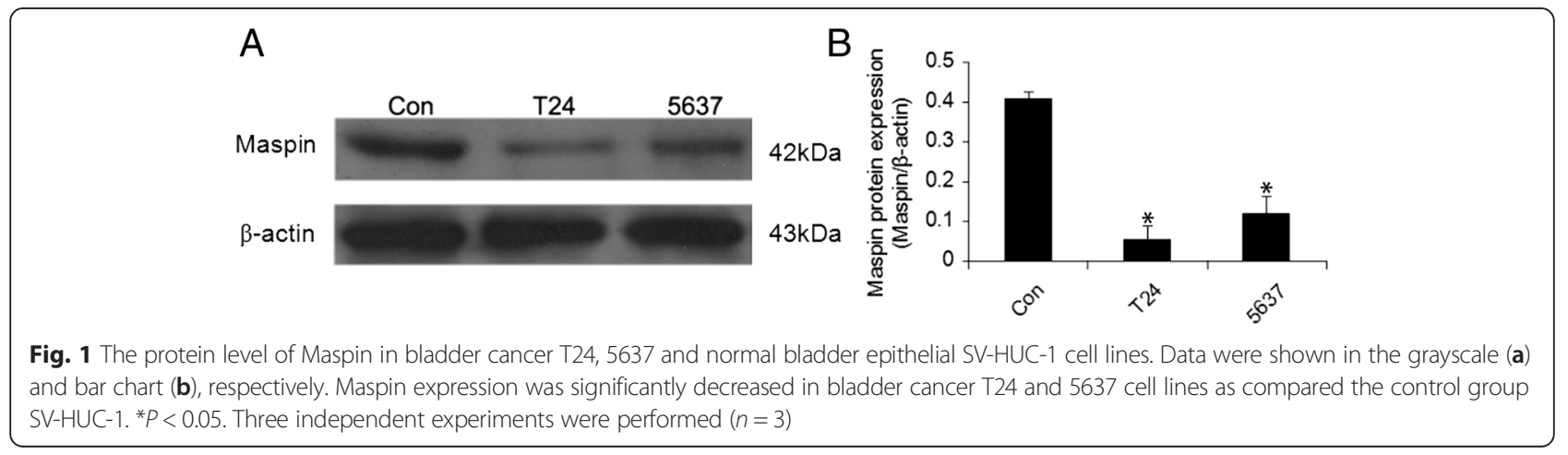



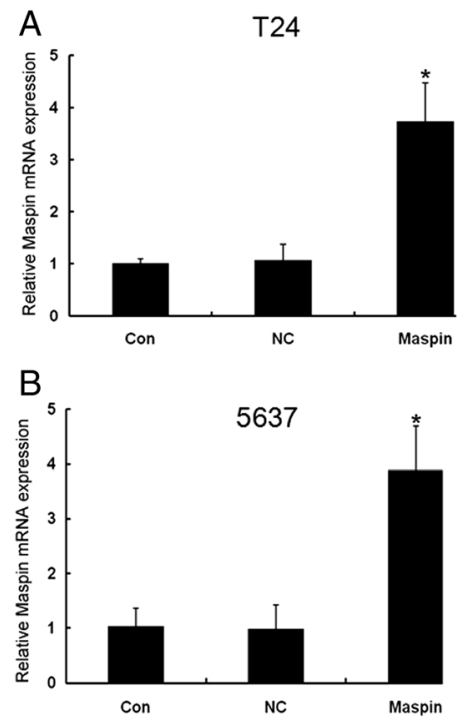

C

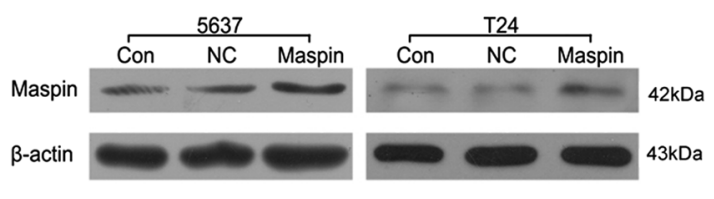

$\mathrm{D}$

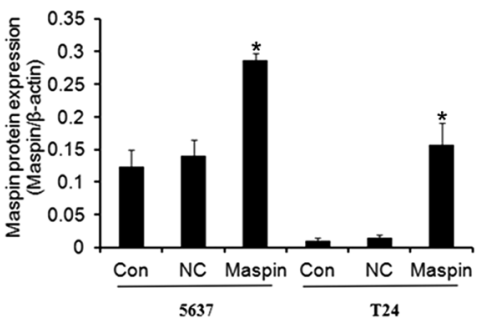

Fig. 2 Expression levels of Maspin post-transfection in bladder cancer T24 and 5637 cells. The mRNA and protein levels of Maspin in bladder cancer T24 and 5637 cells transfected with pcDNA3.1-Maspin or negative control (pcDNA3.1-con) were detected by RT-PCR and western blot. a and $\mathbf{b}$ were showed mRNA level of T24 and 5637 cells, respectively. And $\mathbf{c}$ and $\mathbf{d}$ were showed protein expression level. ${ }^{*} P<0.05$. Three independent experiments were performed $(n=3)$

enviroment. Our results showed that PI3K, which could activate AKT, was downregulated after Maspin overexpression $(P<0.05)$. Though AKT expression did't have significant changes between each three group $(P>0.05)$, p-AKT was decreased after Maspin overexpression $(P<0.05)$. And mTOR, a substrate of the PI3K/AKT signaling pathway, was downregulated in Maspin group $(P<0.05)$. We also found apoptosis related molecules Caspase 3 was increased and Bcl-2 decreased in Maspin group $(P<0.05)$ (Fig. 5).

\section{Maspin expression in the MIBC patient samples}

To assess Maspin expression in the samples of MIBC patient receiving cisplatin based chemotherapy, Maspin protein was detected in the nucleus and cytoplasm of the MIBC specimens. There were 23 (37.1\%) cases of Maspin (+) and $39(62.9 \%)$ cases of Maspin (-) in all MIBC cases (Fig. 6a, b). We also saw the micro-vessels invasion (Fig. 6c) in 41 (66.1\%) cases and lymph node metastasis (Fig. 6d) in 34 (54.8\%) cases.

\section{Maspin expression in correlation with the prognosis of MIBC patients receiving cisplatin based neoadjavant chemotherapy}

To determine if Maspin was associated with the prognosis of MIBC patient receiving cisplatin based neoadjuvant chemotherapy, patients' survival was analyzed with logrank test (Table 2) and Kaplan-Meier survival curves (Fig. 7). In all $62 \mathrm{MIBC}$ patients, the overall survival (OS) rate among the patients with Maspin (-) expression level was potentially significantly lower than that among the patients with Maspin $(+)$ expression $(P=0.0036)$. The progression-free survival (PFS) rate among patients with maspin (-) expression level was also potentially significantly lower than that among the patients with Maspin $(+)$ expression $(P=0.0005)$. These results showed Maspin $(+)$ expression was correlated with good prognosis in MIBC patients who underwent cisplatin based NACT.

\section{Discussion}

Maspin is a $42-\mathrm{kDa}$ protein associated with various tumor related processes such as the inhibition of cell migration, cell invasion, angiogenesis, as well as improvement in cell adhesion and the induction of programmed cell death, thus classifying it as a tumor suppressor [15-17]. Emerging evidence shows that Maspin expression was preserved in superficial bladder cancers and its expression associated with good prognosis. Kramer [18] investigated specimens from 162 non-muscle invasive bladder cancer patients treated by transurethral resection. They showed positive Maspin expression rate was $75.9 \%$ and had a longer PFS compared with negative expression (46 vs 18 months, respectively). And Acikalin, Blandamura also concluded similar results on Maspin expression and superficial bladder cancer [19, 20]. In our study, there were $23(37.1 \%)$ cases of Maspin (+) in 62 MIBC cases. The OS and PFS rate among patients with Maspin (-) were significantly lower than these among patients with Maspin $(+)$ expression $(P=0.0036$ and 0.0005 , respectively). This expression rate was lower than the reported results in superficial bladder cancer 

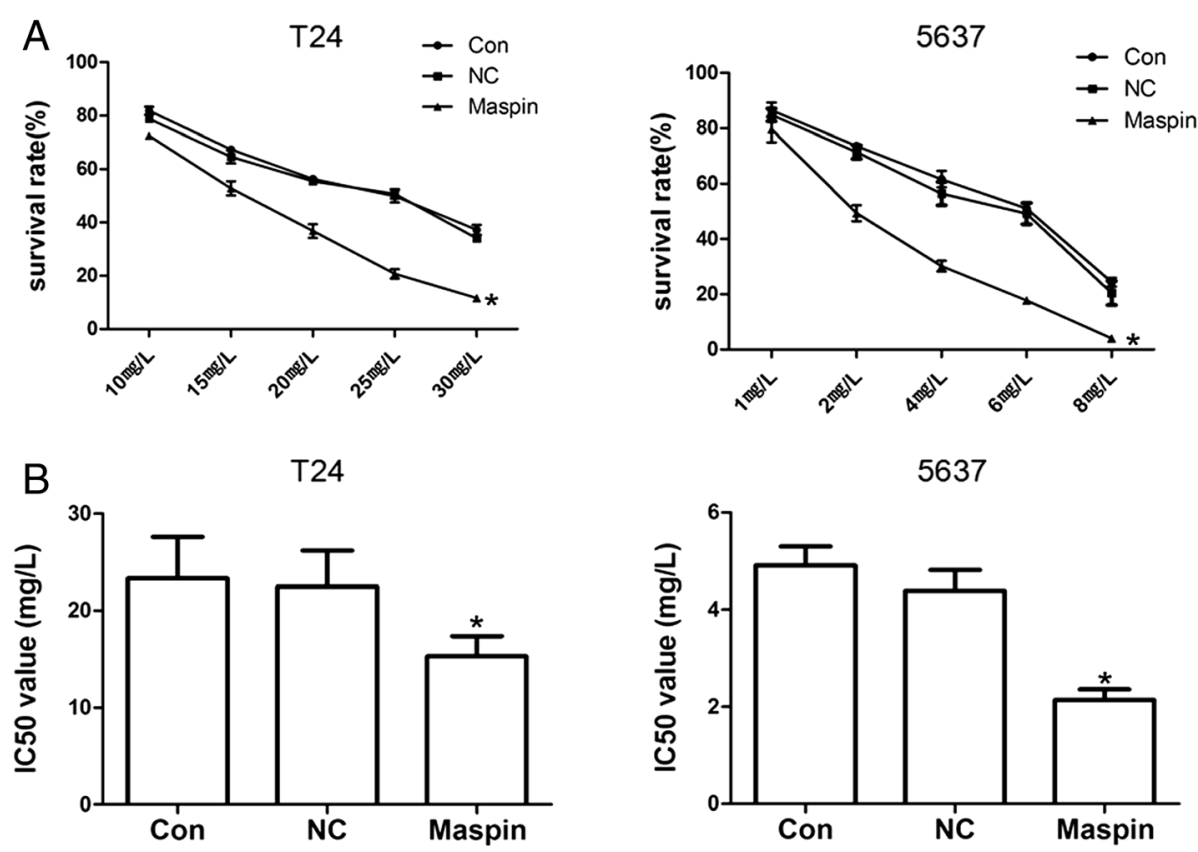

C

T24

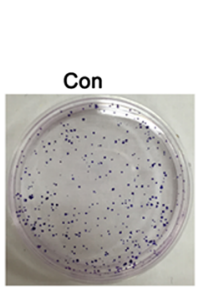

5637

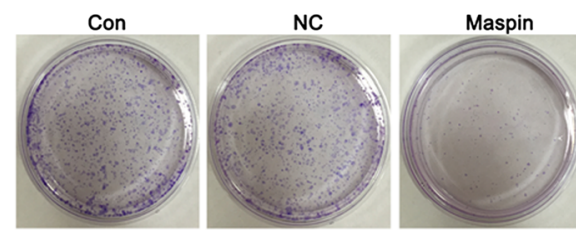

T24

$\mathrm{D}$
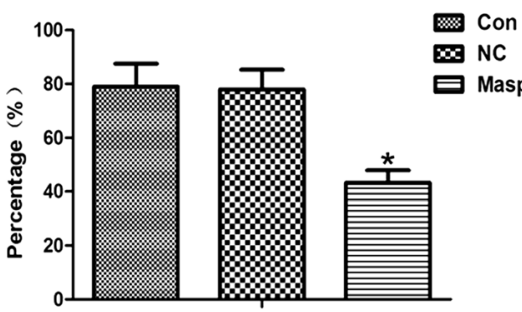

NC

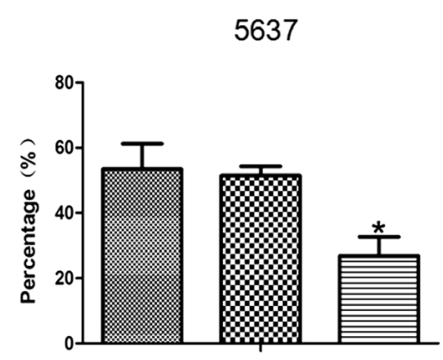

Fig. 3 Effects of Maspin on proliferation and sensitivity to cisplatin of T24 and 5637 cells. a was showed the cell viability with different cisplatin measured by MTT assay. b was showed the IC50 value in each group. Cloning efficiency was calculated after cultured for 2 weeks. c and $\mathbf{d}$ showed the representative results of colony formation assay. Overexpression of Maspin dramatically decreased the cell viability, IC50 value and clone-formation, respectively. ${ }^{*} P<0.05$. Three independent experiments were performed $(n=3)$

while it correlated with the Beecken's study [10], who showed Maspin was significantly diminished in MIBC and patients with high Maspin expression had relatively good prognosis.

Aa a tumor suppressor, Maspin has been found to increase cell apoptosis induced by chemo-regents in several types of cancers. Jiang et al. found Maspin transfected MDA-MB-435 breast carcinoma cells displayed increased sensitivity to staurosporine induced apoptosis
[21]. Ben et al. testified Maspin could mediate E2F1induced apoptosis of U2OS and SAOS2 osteosarcoma cells to doxorubicin and cisplatin [22]. Additional supporting evidence using prostate cancer cells had also reported that Maspin induced apoptosis sensitivity to chemical reagents [23], as well as increased the rate of apoptosis related to inhibition of proteosomal pathways [24].

In addition to surgical treatment, chemotherapy is an important strategy for the therapy of MIBC. Cisplatin 


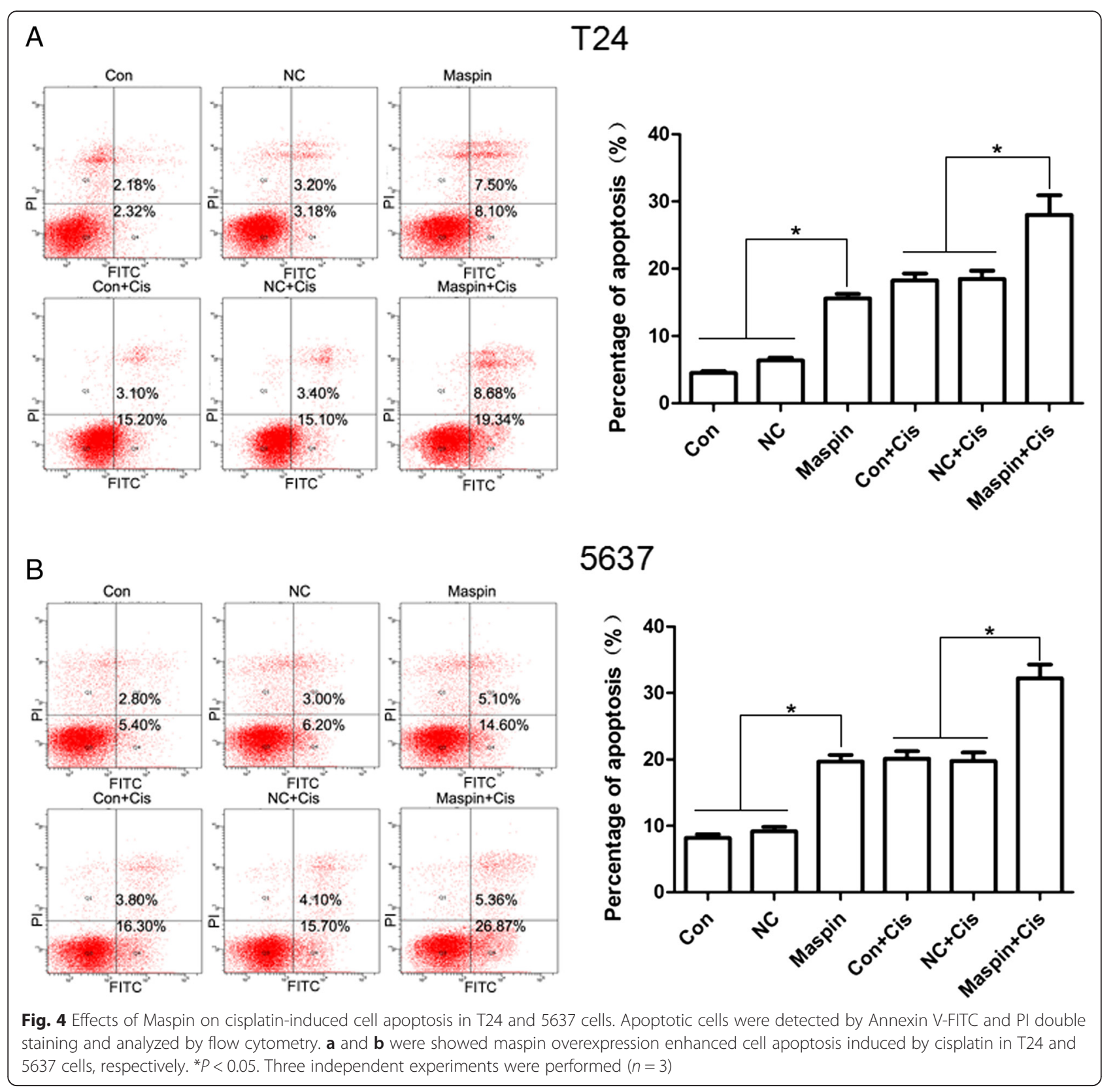

based chemotherapy is widely used in bladder cancer treatment [25]. However, a significant proportion of patients develop disease progression after an initial response to chemotherapy. The drug resistance affect the therapeutic efficacy of bladder cancer treatment [26]. Recently, several molecules and reagents had been found to enhance chemosensitivity in bladder cancer, such as miR-101, TFAP2a, LRIG1, 5-Azacytidine, LY294002, et al. [27-32]. But the crosstalk between Maspin and cisplatin based chemosensitiviy is rare till now. In the present study, our results showed that Maspin overexpression increased the cell apoptosis and enhanced chemosensitivity of both T24 and 5637 cells to cisplatin, with the IC50 value decreasing from $23.32 \pm 4.30 \mathrm{mg} / \mathrm{l}$ to $15.30 \pm 2.10 \mathrm{mg} / \mathrm{l}$ and from $4.91 \pm 0.42 \mathrm{mg} / \mathrm{l}$ to $2.14 \pm$ $0.21 \mathrm{mg} / \mathrm{l}$, respectively. Further more, in MIBC patients treating with NACT plus RC-PLND, Maspin expression was correlated with the prognosis, showing the OS and PFS rates were much longer in Maspin(+) group.

$\mathrm{Bcl}-2$, a $26-\mathrm{kDa}$ integral, is a powerful endogenous anti-apoptosis protein that in response to a variety of cell death signals [33]. Research showed it negatively regulated the activation of Caspase-3, the key executioner of apoptosis, which functions as an effector of mammalian cell death pathways. Downexpression of Bcl-2 promote Caspase activities and apoptosis [34]. The 

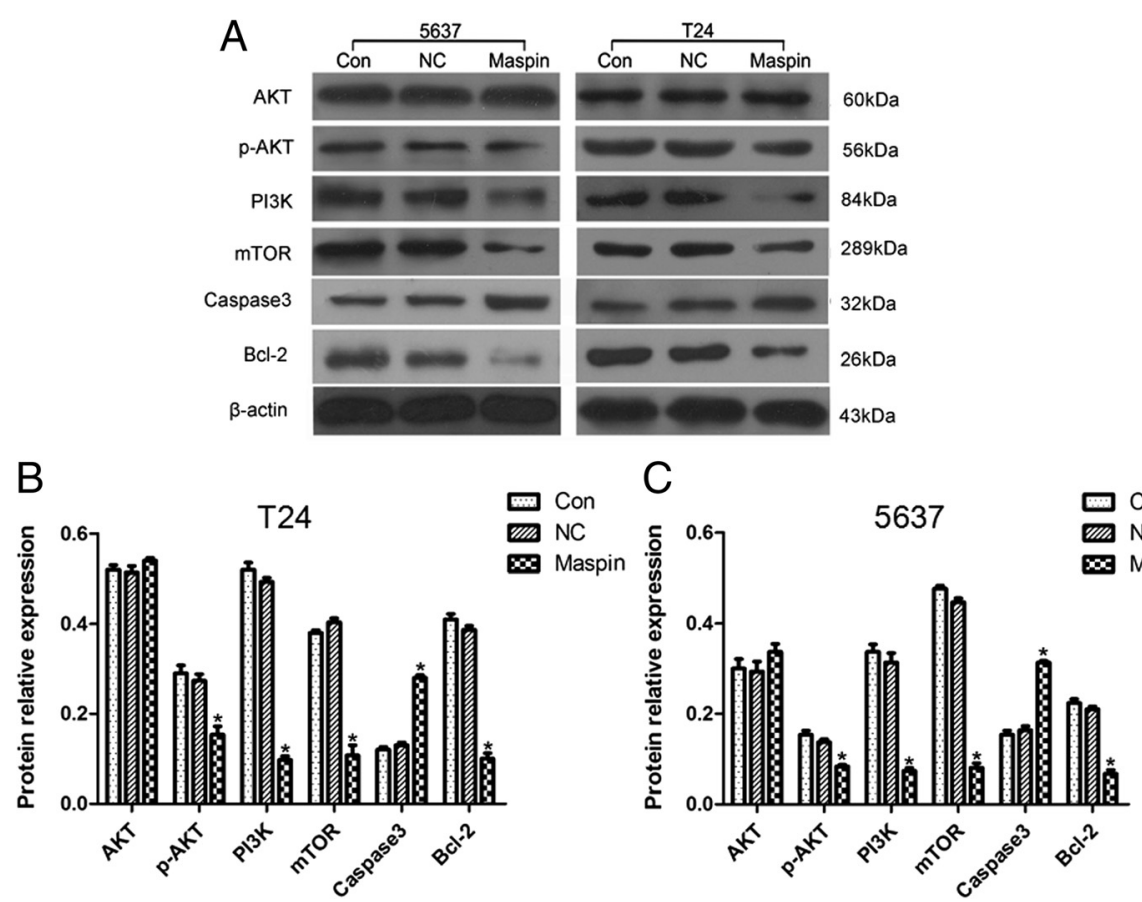

Fig. 5 Western blotting analysis of proteins related to apoptosis in T24 and 5637 cells. a was showed AKT, p-AKT, PI3K, mTOR, Caspase3 and BCl-2 expression in T24 and 5637 cells measured by immunoblotting. And $\beta$-actin was used as an internal control. $\mathbf{b}$ and $\mathbf{c}$ were showed the relative protein levels normalized to $\beta$-actin in T24 and 5637 cells, including Con, NC and Maspin group, respectively. AKT expression did't have significant changes between each three group $(P>0.05)$. p-AKT, PI3K, mTOR, and Bcl-2 expression were significantly decreased, whereas Caspase3 was greatly increased in the Maspin group. ${ }^{*} P<0.05$. Three independent experiments were performed $(n=3)$

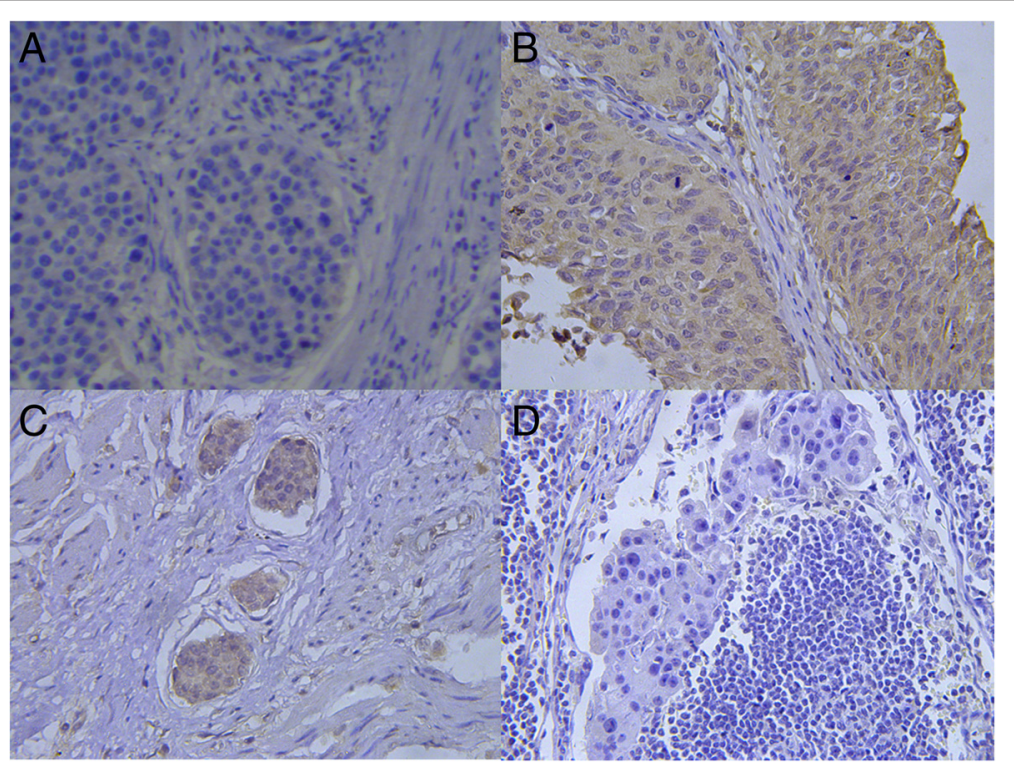

Fig. 6 Immunohistochemistry of bladder cancer tissue with Maspin antibody. a showed negative(-) stain of Maspin in MIBC sample. b showed positive(+) stain of Maspin in MIBC sample. $\mathbf{c}$ showed bladder cancer cells invaded into micro-vessels. $\mathbf{d}$ showed the lymph node metastasis of bladder cancer cells. (a, b, c and $\mathbf{d}$, magnification, $\times 400)$ 
Table 2 Log-rank test of Maspin expression with MIBC survival time

\begin{tabular}{lrll}
\hline Log rank (Mantel-Cox) & \multicolumn{1}{c}{$x^{2}$} & $95 \% \mathrm{Cl}$ & $P$ value \\
\hline Maspin and OS & 8.49 & $1.521-8.515$ & 0.0036 \\
Maspin and PFS & 12.17 & $1.725-6.980$ & 0.0005 \\
\hline
\end{tabular}

OS overall survival, $P F S$ progression-free survival, $C I$ confidence interval. $P<0.05$ was considered statistically significant

present study results show upregulation of the Maspin expression in T24 and 5637 cells, resulting in a decrease in the Bcl-2 level, with a concurrent increase in the Caspase-3 activation. Recent evidence indicates that AKT is frequently activated in many types of human cancer, and activated PI3K/AKT/mTOR signaling pathway

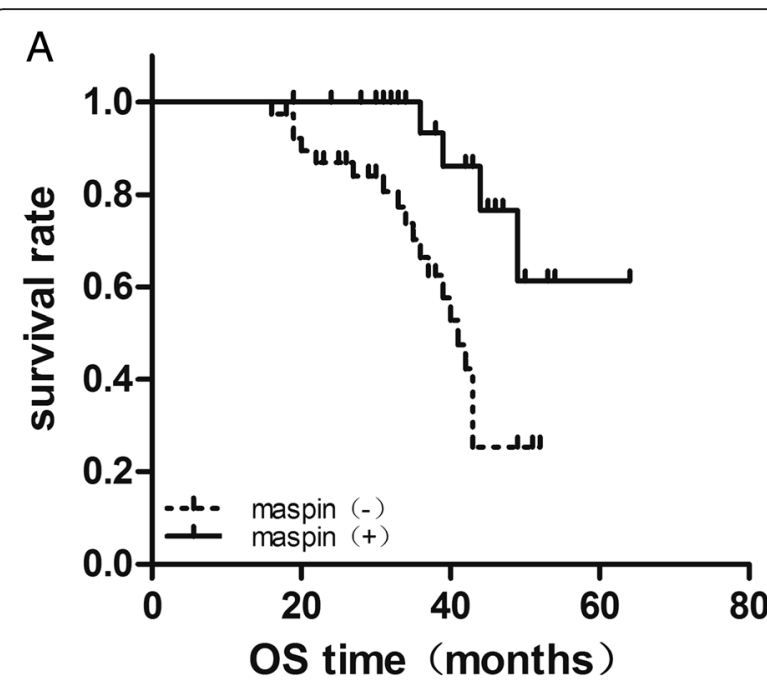

B

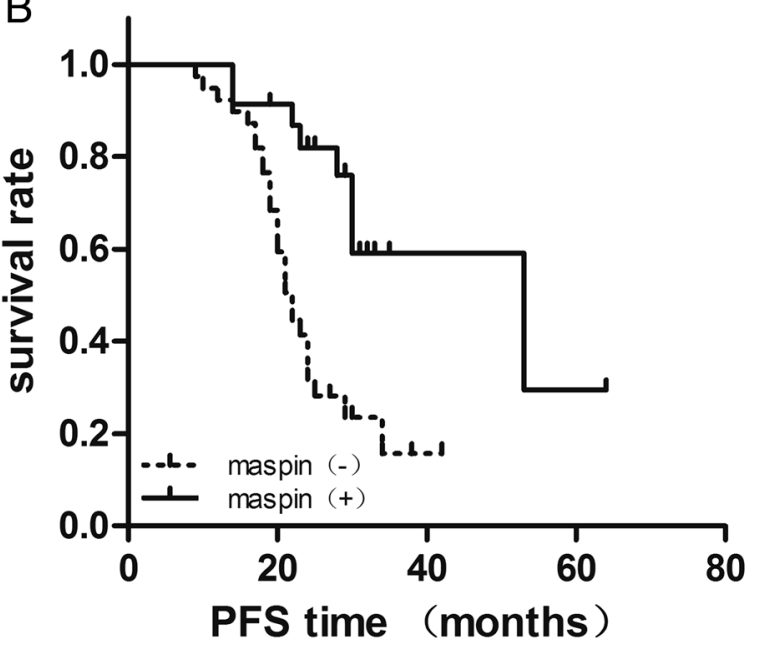

Fig. $\mathbf{7}$ The relationship between Maspin staining and survival rate in MIBC patients receiving NACT plus RC-PLND. $\mathbf{a}$ and $\mathbf{b}$ showed KaplanMeier survival curves of the OS and PFS in the 62 patients, respectively. The results indicated Maspin expression was related to OS and PFS ( $P=0.0036$ and 0.0005 , respectively) is a significant contributor to tumor progression and poor prognosis, including bladder cancer [35]. Moreover, AKT overexpression is often associated with resistance to cisplatin chemotherapy, such as in ovarian and lung cancer, et al. [36, 37]. Sun et al. testified MK2206, a highly potent and selective allosteric AKT inhibitor, could promote the cisplatin-induced cytotoxicity and apoptosis in urothelial cancer cell lines through inhibiting the Akt pathway [38]. $\mathrm{Wu}$ and his colleagues found LY294002, a PI3K inhibitor, could suppress proliferation and sensitize doxorubicin chemotherapy in bladder cancer EJ cells. Our results showed that compared with control group, though AKT expression did't have significant changes, p-AKT, PI3K and mTOR expression were significantly decreased in Maspin group. So, the above results suggest upregulating Maspin expression could enhance cisplatin chemosensitivity and was induced by cell apoptosis through PI3K/ AKT/mTOR signaling pathway in T24 and 5637 cells.

As concluded by Berardi, there are three strategies to re-activate or increase Maspin expression [8]. The first one is designing transcription factors, to hit the system that inhibits the expression of maspin, such as artificial transcription factors (ATFs) and chromatin remodeling drugs [39]. In our previous study, we found a DNA methyltransferase inhibitor, 5-aza-2'-deoxycytidine (5-Aza-CdR), could reactivate Maspin expression and inhibit the proliferation, migration, and invasion of T24 cells, which may serve as a potential strategy for the treatment of bladder cancer [40]. The second one is identifying natural substances that can determine the activation and the expression of Maspin, such as curcumin, a hydrophobic polyphenol derived from turmeric [41]. And Last but not least, gene therapy capable of up-regulating the Maspin in cancer cell, such as Maspin DNA-liposome therapy and adeno-associated virus (AAV, serotype 2) vector encoding Maspin [42, 43].

\section{Conclusions}

In conclusion, Maspin could enhance cisplatin chemosensitivity induced by cell apoptosis in MIBC T24 and 5637 cell lines. The probable mechanism was associated with $\mathrm{PI} 3 \mathrm{~K} / \mathrm{AKT} / \mathrm{mTOR}$ signaling pathway. Its expression correlated with prognosis of MIBC patients who received cisplatin-based NACT. This study provides new insight into Maspin's role in MIBC and shows its promise as a potential molecular target for bladder cancer.

\section{Abbreviations}

MIBC: muscle invasive bladder cancer; NACT: neoadjuvant chemotherapy; OS: overall survival; PFS: progression-free survival; RC-PLND: radical cystectomy and pelvic lymph node dissection.

Competing interests

The authors declare that they have no competing interests. 


\section{Authors' contributions}

JC LW and XZ designed the studies and drafted the manuscript. JC, YT, YC, $C L, X C$ performed the cell experiments. JC, LW, YT, LL, MC, LQ and XZ carried out the clinical studies. GG and ZC performed the statistical analysis. All authors read and approved the final manuscript.

\section{Acknowledgments}

This study was supported by the National Natural Science Foundation of China (No. 81272838 and 81572523).

\section{Author details}

'Department of Urology, Xiangya Hospital, Central South University, Changsha, Hunan 410008, China. ${ }^{2}$ Department of Pathology, Xiangya Hospital, Central South University, Changsha, Hunan 410008, China.

Received: 11 October 2015 Accepted: 30 December 2015 Published online: 06 January 2016

\section{References}

1. Torre LA, Bray F, Siegel RL, Ferlay J, Lortet-Tieulent J, Jemal A. Global cancer statistics, 2012. CA Cancer J Clin. 2015;65(2):87-108.

2. Herr HW. Transurethral resection of muscle-invasive bladder cancer: 10-year outcome. J Clin Oncol. 2001;19(1):89-93.

3. Botteman MF, Pashos CL, Redaelli A, Laskin B, Hauser R. The health economics of bladder cancer: a comprehensive review of the published literature. Pharmacoeconomics. 2003;21:1315-30.

4. Cookson MS, Herr HW, Zhang ZF, Soloway S, Sogani PC, Fair WR. The treated natural history of high-risk superficial bladder cancer: 15-year outcome. J Urol. 1997:158:62-7.

5. Gallagher DJ, Milowsky MI, Bajorin DF. Advanced bladder cancer: status of first-line chemotherapy and the search for active agents in the second-line setting. Cancer. 2008;113(6):1284-93.

6. Witjes JA, Compérat E, Cowan NC, De SM, Gakis G, Lebret T, et al. EAU guidelines on muscle-invasive and metastatic bladder cancer: summary of the 2013 guidelines. Eur Urol. 2014;65(4):778-92.

7. Tanji N, Ozawa A, Miura N, Yanagihara Y, Azuma K, Sasaki T, et al. Long-term results of combined chemotherapy with gemcitabine and cisplatin for metastatic urothelial carcinomas. Int J Clin Oncol. 2010;15(4):369-75.

8. Berardi R, Morgese F, Onofri A, Mazzanti P, Pistelli M, Ballatore Z, et al. Role of maspin in cancer. Clin Transl Med. 2013;2(1):8.

9. Bodenstine TM, Seftor RE, Khalkhali-Ellis Z, Seftor EA, Pemberton PA, Hendrix MJ. Maspin: molecular mechanisms and therapeutic implications. Cancer Metastasis Rev. 2012;31(3-4):529-51.

10. Beecken WD, Engl T, Engels K, Blumenberg C, Oppermann E, Camphausen K, et al. Clinical relevance of maspin expression in bladder cancer. World J Urol. 2006;24(3):338-44.

11. Pawel S, Verena M, Malgorzata GZ, Andrzej W, Irina K, Marek S, et al. Maspin expression is characteristic for cisplatin-sensitive ovarian cancer cells and for ovarian cancer cases of longer survival rates. Int J Gynecol Pathol. 2006; 25(2):131-9

12. Triulzi T, Ratti M, Tortoreto M, Cristina G, Piera A, Viola R, et al. Maspin influences response to doxorubicin by changing the tumor microenvironment organization. Int J Cancer. 2014;134(12):2789-97.

13. Lei KF, Liu BY, Jin XL, Guo Y, Ye M, Zhu ZG. Prognostic value of nuclear maspin expression for adjuvant 5-fluorouracil-based chemotherapy in advanced gastric cancer. Exp Ther Med. 2012;3(6):993-8.

14. Sugimoto S, Maass N, Takimoto Y, Katsuhiko S, Sadatsugu M, Ming Z, et al. Expression and regulation of tumor suppressor gene maspin in human bladder cancer. Cancer Lett. 2004;203(2):209-15.

15. Zou Z, Anisowicz A, Hendrix MJ, Thor A, Neveu M, Sheng S, et al. Maspin, a serpin with tumor-suppressing activity in human mammary epithelial cells. Science. 1994:263(5146):526-9.

16. Zhang M, Volpert $\mathrm{O}$, Shi $\mathrm{YH}$, Bouck N. Maspin is an angiogenesis inhibitor. Nat Med. 2000:6:196-9.

17. Lockett J, Yin S, Li X, Meng Y, Sheng S. Tumor suppressive maspin and epithelial homeostasis. J Cell Biochem. 2006;97:651-60.

18. Kramer MW, Waalkes S, Hennenlotter J, Serth J, Stenzl A, Kuczyk MA, et al. Maspin protein expression correlates with tumor progression in non-muscle invasive bladder cancer. Oncol Lett. 2010;1(4):621-6.
19. Acikalin D, Oner U, Can C, Acikalin MF, Colak E. Predictive value of maspin and $\mathrm{Ki}-67$ expression in transurethral resection specimens in patients with T1 bladder cancer. Tumori. 2012;98(3):344-50.

20. Blandamura S, D'Alessandro E, Giacomelli L, Guzzardo V, Battanello W, Repele M, et al. Expression of maspin in papillary Ta/T1 bladder neoplasms. Anticancer Res. 2008:28:471-8.

21. Jiang N, Meng Y, Zhang S, Mensah OE, Sheng S. Maspin sensitizes breast carcinoma cells to induced apoptosis. Oncogene. 2002;21:4089-98.

22. Ben Shachar B, Feldstein O, Hacohen D, Ginsberg D. The tumor suppressor maspin mediates E2F1-induced sensitivity of cancer cells to chemotherapy. Mol Cancer Res. 2010;8:363-372.

23. Tahmatzopoulos A, Sheng S, Kyprianou N. Maspin sensitizes prostate cancer cells to doxazosin-induced apoptosis. Oncogene. 2005;24:5375-83

24. Li X, Chen D, Yin S, Meng Y, Yang H, Landis-Piwowar KR, et al. Maspin augments proteasome inhibitor-induced apoptosis in prostate cancer cells. J Cell Physiol. 2007:212:298-306.

25. Costantini C, Millard F. Update on chemotherapy in the treatment of urothelial carcinoma. Scientific World Journal. 2011:11:1981-94.

26. Galluzzi L, Vitale I, Michels J, Brenner C, Szabadkai G, Harel-Bellan A, et al. Systems biology of cisplatin resistance: past, present and future. Cell Death Dis. 2014;5, e1257.

27. Ye L, Bin L, Shiyu T, Lin Q, Xiheng H, Yunbo C, et al. miR-101 suppresses vascular endothelial growth factor $C$ that inhibits migration and invasion and enhances cisplatin chemosensitivity of bladder cancer cells. PloS One. 2015;10(2):e0117809.

28. Nordentoft I, Dyrskjøt L, Bødker JS, Wild PJ, Hartmann A, Bertz S, et al. Increased expression of transcription factor TFAP2 correlates with chemosensitivity in advanced bladder cancer. BMC Cancer. 2011;11:135.

29. Yan Z, Jiang J, Li F, Yang W, Xie G, Zhou C, et al. Adenovirus-mediated LRIG1 expression enhances the chemosensitivity of bladder cancer cells to cisplatin. Oncol Rep. 2015:33(4):1791-8.

30. Kavitha R, Edna G, Rakesh S. 5-azacytidine reverses drug resistance in bladder cancer cells. Anticancer Res. 2011:31(11):3757-66.

31. Zhou H, Tang K, Xiao H, Zeng J, Guan W, Guo X, et al. A panel of eight-miRNA signature as a potential biomarker for predicting survival in bladder cancer. J Exp Clin Cancer Res. 2015;34:53.

32. Wu D, Tao J, Xu B, Oing W, Li P, Lu Q et al. Phosphatidylinositol 3kinase inhibitor LY294002 suppresses proliferation and sensitizes doxorubicin chemotherapy in bladder cancer cells. Urol Int. 2011;86(1): $346-54$.

33. Hockenbery DM, Zutter M, Hickey W, Nahm M, Korsmeyer SJ. BCL2 protein is topographically restricted in tissues characterized by apoptotic cell death. Proc Natl Acad Sci U S A. 1991;88(16):6961-5.

34. Gross $\mathrm{A}, \mathrm{McD}$ onnell JM, Korsmeyer $\mathrm{SJ}$. BCL-2 family members and the mitochondria in apoptosis. Genes Dev. 1999;13:1899-911.

35. Sun $\mathrm{CH}$, Chang YH, Pan CC. Activation of the PI3K/Akt/mTOR pathway correlates with tumour progression and reduced survival in patients with urothelial carcinoma of the urinary bladder. Histopathology. 2011:58: 1054-63.

36. Yang X, Fraser M, Moll UM, Ajoy B, Tsang BK. Akt-mediated cisplatin resistance in ovarian cancer: modulation of p53 action on caspase-dependent mitochondrial death pathway. Cancer Res, 2006:66:3126-36.

37. Liu LZ, Zhou XD, Qian G, Shi X, Fang J, Jiang BH. AKT1 amplification regulates cisplatin resistance in human lung cancer cells through the mammalian target of rapamycin/p70S6K1 pathway. Cancer Res. 2007;67: $6325-32$

38. Sun D, Sawada A, Nakashima M, Kobayashi T, Ogawa O, Matsui Y. MK2206 potentiates cisplatin-induced cytotoxicity and apoptosis through an interaction of inactivated Akt signaling pathway. Urol Oncol. 2015;33(3): 111.e17-26.

39. Beltran A, Parikh $\mathrm{S}$, Liu Y, Cuevas BD, Johnson GL, Futscher BW, et al. Re-activation of a dormant tumor suppressor gene maspin by designed transcription factors. Oncogene. 2007:26:2791-8.

40. Zhang H, Qi F, Cao Y, Zu X, Chen M, Li Z, et al. 5-Aza-2'-deoxycytidine enhances maspin expression and inhibits proliferation, migration, and invasion of the bladder cancer T24 cell line. Cancer Biother Radiopharm. 2013;28:343-50.

41. Anand P, Sundaram C, Jhurani S, Kunnumakkara AB, Aggarwal BB. Curcumin and cancer: an "old-age" disease with an "age-old" solution. Cancer Lett. 2008;267:133-64. 
42. Schaefer JS, Zhang M. Targeting maspin in endothelial cells to induce cell apoptosis. Expert Opin Ther Targets. 2006;10(3):401-8.

43. Watanabe M, Nasu Y, Kashiwakura Y, Nasu Y, Kashiwakura Y, Kusumi N, et al. Adeno-associated virus 2-mediated intratumoral prostate cancer gene therapy: long-term maspin expression efficiently suppresses tumor growth. Hum Gene Ther. 2005;16(6):699-710.

Submit your next manuscript to BioMed Central and we will help you at every step:

- We accept pre-submission inquiries

- Our selector tool helps you to find the most relevant journal

- We provide round the clock customer support

- Convenient online submission

- Thorough peer review

- Inclusion in PubMed and all major indexing services

- Maximum visibility for your research

Submit your manuscript at www.biomedcentral.com/submit 